\title{
THE RESPIRATORY DISTRESS SYNDROME OF THE NEWBORN: IMMATURITY VERSUS PREMATURITY
}

BY

\author{
PETER M. DUNN* \\ From The Birmingham Maternity Hospital
}

(RECEIVED FOR PUBLICATION MAY 4, 1964)

The respiratory distress syndrome (RDS) remains the most important cause of morbidity and mortality among anatomically normal infants during the first few days of life. There is no general agreement as to the aetiology or pathogenesis of this condition. However, its association with a number of maternal and foetal factors is well recognized; foremost among these is prematurity. While the definition of the premature infant is based on low birth weight ( $5 \mathrm{lb} .8 \mathrm{oz} .(2.5 \mathrm{~kg}$.) or less), the term is often used loosely to denote immaturity. This may lead to confusion, for immature infants may be heavier than the average full-term baby. At the same time, about one-third of all 'premature' infants born in this country have had a gestation of 38 weeks or more (Butler and Bonham, 1963).

In this paper, a study has been made of the relative importance of birth weight and length of gestation on the incidence of RDS and its mortality.

\section{Subjects and Method}

All infants of 28 weeks gestation or more who were born alive in this hospital during 1961 were admitted to the study. Length of gestation was reckoned in terms of weeks completed since the first day of the last menstrual period. When this date was in doubt, the obstetrician's antenatal judgment was accepted. If, however, clinical examination of a newborn infant suggested that the estimated length of gestation was incorrect by at least a month, then a suitable adjustment was made. This was thought necessary for between 6 and $7 \%$ of all deliveries. Seven $(9 \cdot 5 \%)$ of the infants who developed RDS were involved; in each case radiological assessment of bone age was also obtained.

All babies were weighed and examined on the first day of life. Small or sick infants were usually seen at or soon after birth. Records on every baby were kept by the author who examined approximately $97 \%$ of those born alive. Information on the remainder was obtained from the case notes.

The diagnosis of RDS was based on the characteristic clinical picture and course of the disease, an excellent

\footnotetext{
* Present address: Royal Hospital for Sick Children, Bristol.
}

description of which has been given by Usher (1961a). All the affected infants showed oedema, diminished air entry on auscultation, and dyspnoea with inspiratory retraction. The great majority demonstrated expiratory grunting and tachypnoea after the first hour of life; many became cyanosed. Infants that also suffered from coexistent disease, such as $\mathrm{Rh}$ incompatibility, were not excluded. However, infants, usually fairly mature, showing transient signs of respiratory distress that subsided within six hours of birth, have not been included as cases of RDS. Four previable infants (less than 28 weeks gestation) who showed respiratory distress during life and complete primary atelectasis after death have also been excluded from this study.

With one exception, necropsy was performed on all infants born in this period that died during the first week of life. In the case of every infant thought to have suffered from RDS, post-mortem examination confirmed the presence of atelectasis and venous congestion; with the exception of two of the most immature infants, there was also pulmonary congestion, alveolar duct distension, and resorption atelectasis with or without hyaline membrane formation.

At the time of the study, RDS was treated in this hospital with oxygen, digoxin, and antibiotics.

\section{Results}

During 1961, 2,051 infants were born alive after a gestation of 28 weeks or more; and $49(2 \cdot 4 \%)$ died during the neonatal period.

In Table 1, infants are grouped according to birth weight $( \pm 2,500$ g. $)$ and length of gestation $( \pm 37$ weeks or 259 days). The distribution of the deaths is also shown. Thus, $11 \cdot 6 \%$ of all infants weighed less than $2,500 \mathrm{~g}$. at birth, while $10 \cdot 5 \%$ were born before 37 weeks. The number of deaths in each group was the same, $77 \cdot 5 \%$ of the total neonatal mortality.

Fig. 1 shows the distribution of all births and deaths according to length of gestation. The heavy toll among the most immature infants decreases sharply at first and then more slowly until it reaches an average low of $0.5 \%$ between 38 and 41 weeks. 


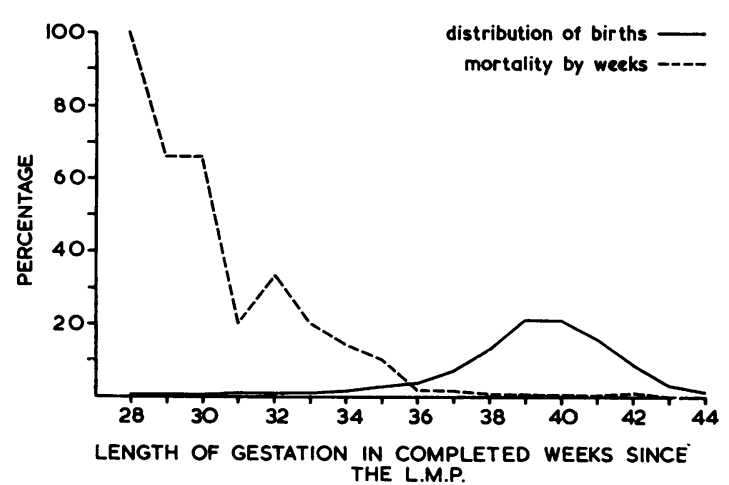

FIG. 1.-Distribution according to length of gestation of 2,051 infants born alive after the 28 th week. The neonatal mortality at weekly intervals is also shown.

Respiratory Distress Syndrome. 76 infants were diagnosed as suffering from this disease and 31 $(40 \cdot 8 \%)$ of them died. A second diagnosis was present in 13 cases (non-traumatic intracranial haemorrhage in $8, \mathrm{Rh}$ haemolytic disease in 2 , infection in 2, and massive pulmonary haemorrhage in 1). These 31 deaths represent $63 \%$ of all the neonatal deaths, $81 \cdot 5 \%$ of those among infants born before 37 weeks' gestation and $73.5 \%$ of those weighing $2,500 \mathrm{~g}$. or less at birth.

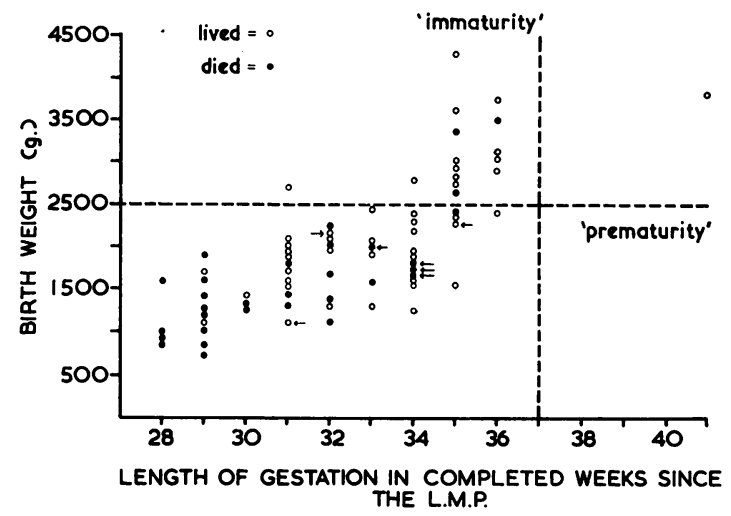

FIG. 2.-The birth weight, length of gestation, and fate of the $\mathbf{7 6}$ infants with the repiratory distress syndrome. Arrows mark the cases in which the antenatal estimate of length of gestation has been corrected after birth in the direction shown.

Table 2 is similar to Table 1 except that only infants with RDS are represented. Fig. 2 shows the length of gestation, birth weight, and fate of these babies; $97 \cdot 3 \%$ of them (and all that died) were of less than 37 weeks' gestation. Low birth weight was present in only $77 \cdot 5 \%$ of cases and in $90 \%$ of deaths.

The incidence of RDS, according to length of gestation, is plotted in Fig. 3, as is also the mortality from this disease. It can be seen that RDS not

TABLE 1

LIVE BIRTHS AND NEONATAL DEATHS IN RELATION TO BIRTH WEIGHT AND LENGTH OF GESTATION

\begin{tabular}{|c|c|c|c|c|c|c|}
\hline \multirow{3}{*}{ Gestation } & \multicolumn{4}{|c|}{ Birth Weight } & \multirow{2}{*}{\multicolumn{2}{|c|}{ Total }} \\
\hline & \multicolumn{2}{|c|}{$<2,500 \mathrm{~g}$} & \multicolumn{2}{|c|}{$>2,500 \mathrm{~g}$} & & \\
\hline & Infants & Deaths & Infants & Deaths & Infants & Deaths \\
\hline$<37$ weeks (259 days) & $135(6 \cdot 5)$ & $35(71 \cdot 5)$ & $81(4 \cdot 0)$ & $3(6 \cdot 1)$ & $216(10 \cdot 5)$ & $38(77 \cdot 5)$ \\
\hline 37 weeks or more & $102(5 \cdot 0)$ & $3(6 \cdot 1)$ & $1,733(84 \cdot 5)$ & $8(16 \cdot 3)$ & $1,835(89 \cdot 5)$ & $11(22 \cdot 5)$ \\
\hline Total ... & $237(11 \cdot 6)$ & $38(77 \cdot 5)$ & $1,814(88 \cdot 4)$ & $11(22 \cdot 5)$ & $2,051(100)$ & $49(100)$ \\
\hline
\end{tabular}

Percentages of all infants and of all deaths are shown in brackets.

TABLE 2

INCIDENCE OF RDS AND MORTALITY FROM IT IN RELATION TO BIRTH WEIGHT AND LENGTH OF GESTATION

\begin{tabular}{|c|c|c|c|c|c|c|}
\hline \multirow{3}{*}{ Gestation } & \multicolumn{4}{|c|}{ Birth Weight } & \multirow{2}{*}{\multicolumn{2}{|c|}{ Total }} \\
\hline & \multicolumn{2}{|c|}{$<2,500 \mathrm{~g}}$. & \multicolumn{2}{|c|}{$>2,500 \mathrm{~g}$} & & \\
\hline & Infants & Deaths & Infants & Deaths & Infants & Deaths \\
\hline$<37$ weeks (259 days) & $59(77 \cdot 5)$ & $28(90 \cdot 3)$ & $15(19 \cdot 8)$ & $3(9 \cdot 7)$ & $74(97 \cdot 3)$ & $31(100)$ \\
\hline 37 weeks or more $\ldots$ & $0(0)$ & $0(0)$ & $2(2 \cdot 7)$ & $0(0)$ & $2(2 \cdot 7)$ & $0(0)$ \\
\hline Total $\ldots$ & $59(77 \cdot 5)$ & $28(90 \cdot 3)$ & $17(22 \cdot 5)$ & $3(9 \cdot 7)$ & $76(100)$ & $31(100)$ \\
\hline
\end{tabular}

Percentages are shown in brackets. 


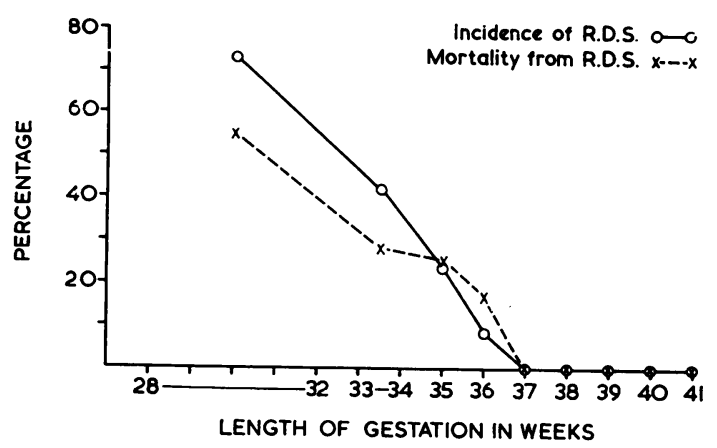

FIG. 3.-Incidence of the respiratory distress syndrome and the mortality from this disease in relation to length of gestation.

only becomes more common with decreasing maturity, but is also more liable to be fatal.

\section{Discussion}

The Birmingham Maternity Hospital receives obstetric problems from a wide area. For example, the incidence of $\mathrm{Rh}$ haemolytic disease in this hospital during the period under study was over eight times as great as for the country as a whole. The incidence of prematurity was, however, only twice the national average. This was due to the deliberate policy of not admitting women in uncomplicated premature labour in order to conserve nursery space. As a result, the great majority of premature infants were born following an abnormal pregnancy or complicated delivery.

Thus, no less than $24.5 \%$ of the 'immature' infants in this series were delivered by caesarean section. These factors, which will be discussed in greater detail in a further communication, help to explain the very high incidence of RDS in this study; at $3 \cdot 7 \%$ this was at least twice as high as that in any of the four other maternity units in which the author has worked. For the same reasons, the neonatal mortality rate was also high $(1 \cdot 7 \times$ the national average), though in fact the lowest recorded for this hospital during a 15-year period.

The neonatal mortality among the $90 \%$ of infants who were born after the 37 th week ( 259 days) was $0 \cdot 6 \%$ or, if deaths due to gross congenital malformation are excluded, only $0.38 \%$. The neonatal mortality for all births in England and Wales during 1961 was $1 \cdot 5 \%$. When it is recalled that virtually every pregnancy in this study was complicated in one way or another, it will be appreciated how tough the mature newborn infant is and how well equipped to adapt himself to extrauterine life.
In contrast, the mortality among the $10 \%$ of infants delivered before 37 weeks' gestation was nearly 29 times as great at $17 \cdot 6 \%$. RDS was the main cause of death in four-fifths of cases. Though this disease has been called one of prematurity, this description only appears to be accurate in so far as babies of low birth weight are usually also immature. Where, in this study, immature infants were relatively heavy at birth (usually in association with maternal diabetes), the risk from RDS remained. In fact, $22.5 \%$ of the infants having RDS weighed more than $2,500 \mathrm{~g}$. at birth, while only $2 \cdot 7 \%$ were of more than 37 weeks' gestation. This is in close agreement with the observations of Usher (1961b) and Usher, McLean, and Maughan (1964). Though 43\% of 'premature' infants were delivered after the 37 th week (Table 1), none developed RDS: it must be admitted, however, that five RDS infants have been removed from this group because it was felt reasonably certain that their maturity was less than had been expected (Fig. 2).

The very rapid decrease in mortality from the limits of viability at 28 weeks down to $1 \%$ at 37 weeks, only 63 days later, is shown in Fig. 1. Approximate$1 y$, this implies that for every day less that the foetus remained in utero between the 31 st and 37 th weeks of gestation, its chances of dying in the neonatal period increased by $1 \%$. Between 28 and 31 weeks, the chance of death increased at twice this rate. For this reason, when induction of labour or caesarean delivery is contemplated because of foetal indications, the dangers of a continued intrauterine existence must be balanced with great care against those of immaturity. Every day is important. Decisions may be difficult enough when the length of gestation can be estimated with confidence. Unfortunately, this confidence is frequently lacking. In this study, the author estimated that between 6 and $7 \%$ of infants were either a month less or more mature than had been expected. The size of this group is less surprising when it is remembered that half the pregnant women in this country attend their doctor for the first time after the first four months of pregnancy (Butler and Bonham, 1963) and another half rely completely on memory for the accuracy of their 'dates' (unpublished data). In addition, the menstrual history may mislead in many ways. The price of a misjudgment may be an unexpectedly immature infant that dies from RDS. This type of tragedy occurred on four occasions in this study. Postnatal examination showed that the bone age was about four weeks less than expected in every case. Bone development is making such huge strides during the last trimester of pregnancy that antenatal radiological assessment of maturity may be of great 
assistance (Hartley, 1957). At the worst, radiological interpretation is extremely unlikely to mislead by as much as four weeks. Unfortunately, this useful aid is sometimes withheld because of fear of damage to the foetus from irradiation (Brown, Doll, and Hill, 1960). Without denying this risk, its dangers seem to be much smaller and less immediate than those of immaturity and RDS.

\section{Summary}

The effect of birth weight and length of gestation on the occurrence of the respiratory distress syndrome of the newborn was studied in a maternity hospital.

The incidence of this disease was related to low birth weight only in so far as the latter was related to immaturity. RDS was rare after the 37 th week of gestation (259 days), providing the mothers' dates were correct. Before this time, both the incidence of this disease and the mortality from it rose steeply with decreasing maturity. It was, in the main, responsible for four-fifths of the neonatal deaths among immature infants.

I would like to thank Dr. B. S. B. Wood both for his helpful criticism and for permission to publish this case material; also the Consultant Obstetricians of the Birmingham Maternity Hospital for allowing me access to their case records, and Dr. H. G. Kohler for his thorough post-mortem reports.

\section{REFERENCES}

Brown, W. M. Court, Doll, R., and Hill, A. Bradford (1960). Incidence of leukaemia after exposure to diagnostic radiation in utero. Brit. med. J., 2, 1539.

Butler, N. R., and Bonham, D. G. (1963). Perinatal Mortality. The First Report of the 1958 British Perinatal Mortality Survey, pp. 62, 142. Livingstone, London.

Hartley, J. B. (1957). Radiological estimation of foetal maturity. Brit. J. Radiol., 30, 561.

Usher, R. H. (1961a). Clinical investigation of the respiratory distress syndrome of prematurity. N.Y. St. J. Med., 61, 1677. - (1961b). The respiratory distress syndrome of prematurity: Clinical and therapeutic aspects. Pediat. Clin. N. Amer., 8, 525.

—, McLean, F., and Maughan, G. B. (1964). Respiratory distress syndrome in infants delivered by cesarean section. Amer. J. Obstet. Gynec., 88, 806. 